\title{
Evaluating the effect of magnesium supplementation and cardiac arrhythmias after acute coronary syndrome: a systematic review and meta-analysis
}

\author{
Shirvan Salaminia ${ }^{1}$, Fatemeh Sayehmiri ${ }^{2}$, Parvin Angha ${ }^{3}$, Koroush Sayehmiri $^{4}$ and Morteza Motedayen ${ }^{5^{*}}$ (D)
}

\begin{abstract}
Background: Atrial and ventricular cardiac arrhythmias are one of the most common early complications after cardiac surgery and these serve as a major cause of mortality and morbidity after cardiac revascularization. We want to evaluate the effect of magnesium sulfate administration on the incidence of cardiac arrhythmias after cardiac revascularization by doing this systematic review and meta-analysis.

Methods: The search performed in several databases (SID, Magiran, IranDoc, IranMedex, MedLib, PubMed, EmBase, Web of Science, Scopus, the Cochrane Library and Google Scholar) for published Randomized controlled trials before December 2017 that have reported the association between Magnesium consumption and the incidence of cardiac arrhythmias. This relationship measured using odds ratios (ORs) with a confidence interval of $95 \%$ (Cls). Funnel plots and Egger test used to examine publication bias. STATA (version 11.1) used for all analyses.

Results: Twenty-two studies selected as eligible for this research and included in the final analysis. The total rate of ventricular arrhythmia was lower in the group receiving magnesium sulfate than placebo (11.88\% versus $24.24 \%$ ). The same trend obtained for the total incidence of supraventricular arrhythmia (10.36\% in the magnesium versus $23.91 \%$ in the placebo group). In general the present meta-analysis showed that magnesium could decrease ventricular and supraventricular arrhythmias compared with placebo $(\mathrm{OR}=0.32,95 \% \mathrm{Cl} 0.16-0.49 ; p<0.001$ and $\mathrm{OR}=0.42,95 \% \mathrm{Cl} 0.22-0.65 ; \mathrm{p}<0.001$, respectively). Subgroup analysis showed that the effect of magnesium on the incidence of cardiac arrhythmias was not affected by clinical settings and dosage of magnesium. Meta-regression analysis also showed that there was no significant association between the reduction of ventricular arrhythmias and sample size.
\end{abstract}

Conclusion: The results of this meta-analysis study suggest that magnesium sulfate can be used safely and effectively and is a cost-effective way in the prevention of many of ventricular and supraventricular arrhythmias.

Keywords: Serum magnesium level, Arrhythmias, Atrial, Ventricular, Meta-analysis

\footnotetext{
* Correspondence: mor.mot2@gmail.com

${ }^{5}$ Department of Cardiology, Faculty of Medicine, Zanjan University of Medical

Sciences, Zanjan, Iran

Full list of author information is available at the end of the article
}

(c) The Author(s). 2018 Open Access This article is distributed under the terms of the Creative Commons Attribution 4.0 International License (http://creativecommons.org/licenses/by/4.0/) which permits unrestricted use, distribution, and reproduction in any medium, provided you give appropriate credit to the original author(s) and the source, provide a link to the Creative Commons license, and indicate if changes were made. The Creative Commons Public Domain Dedication waiver (http://creativecommons.org/publicdomain/zero/1.0/) applies to the data made available in this article, unless otherwise stated. 


\section{Background}

Coronary artery disease is one of the major causes of death in most industrialized and also other countries. Despite newer medical treatments as well as interventional and surgical techniques, mortality is still significant. In addition to medical treatments for this disease, many patients with the coronary artery disease need surgical treatment. Coronary artery bypass graft is an effective procedure to reduce or eliminate symptoms of angina. However, despite being effective, it also has special complications during and following surgery. One of the most common early complications after open heart surgery is atrial and ventricular arrhythmias, which leads to increased mortality and morbidity in the postoperative period. This complication by increasing hospital stay, it also raises the involved economic costs [1]. The use of cardiopulmonary bypass, as one of the essentials for coronary bypass graft, results in decreased serum magnesium level. Hypomagnesemia is a relatively common electrolyte disorder in hospitalized patients[2] with associated arrhythmias. The arrhythmias which caused by magnesium deficiency are resistant to both antiarrhythmic drugs and cardioversion[3]. As a result, the addition of magnesium sulfate to compensate for Hypomagnesemia could be a method for preventing arrhythmias. During cardiopulmonary bypass, total Magnesium concentration reduces due to the ultrafiltration and also hydration with Albumin and other blood products. However, increasing renal excretion of magnesium does not occur during bypass[4].

Magnesium deficiency presents among about $71 \%$ of patients who underwent Cardiopulmonary bypass (CPB) [5]. In many studies intraoperative addition of the magnesium sulfate was beneficial. These benefits were decreasing postoperative arrhythmia rate; lowering the rate of postoperative hypertension and reducing postoperative electrocardiographic changes [6]; increasing coronary blood flow and increased cardiac indexes [7], reduced inflammatory response [8], decreased platelet function [9], and reduced mortality [10].

There is evidence to suggest that low magnesium level could relate to the incidence of ventricular arrhythmias after cardiac surgery and may reduce postoperative ventricular arrhythmia. However, there are different opinions about the relationship between magnesium level and the Arrhythmia in patients with acute coronary syndromes [11]. Many studies performed in this regard and some of them showed relation.

In this systematic review and meta-analysis study, it has been tried to integrate the results of studies that investigate the effect of magnesium sulfate on cardiac arrhythmias. The fundamental aim is to provide a safe and effective way for prevention of cardiac arrhythmias and its complications.

\section{Methods}

\section{Data sources and search strategy}

The present study is a meta-analysis of all data resources about the effect of magnesium sulfate on cardiovascular events after coronary revascularization. The study conducted by the review and meta-analysis of existing electronic sources between 1986 and 2017, including SID, Magiran, IranDoc, IranMedex, MedLib, PubMed, ISI, Web of Science, Scopus, and Google Scholar. The selected studies must evaluate the effect of magnesium sulfate on cardiac arrhythmias and mortality after cardiac revascularization and in both Farsi and English languages. Our keywords were magnesium sulfate, bypass, coronary artery, arrhythmia, atrial, ventricular and their Persian equivalents and with all their possible combinations. Also, all titles and references of the selected articles used as additional search tools for relevant studies.

\section{Study selection) inclusion and exclusion criteria)}

This review considered all randomized controlled trials which evaluated the relationship between magnesium sulfate with cardiac arrhythmias. Inclusion criteria were as follow: any study carried out in the patients with acute coronary syndromes (all patients undergoing CABG or PCI and also medically treated subjects); evaluated the correlation of the arrhythmias and serum magnesium sulfate; compared the administration of magnesium to a placebo group, and reported clinical events such as incidence and type of arrhythmias (supraventricular arrhythmias / ventricular arrhythmias) and or mortality. Any study excluded if was in conjunction with another heart disease; not reported the incidence of arrhythmias, were case studies, and those not compared magnesium with placebo. Also, studies excluded if published in languages other than English or Persian, those that were meta-analyses or systematic reviews, and those that presented insufficient data or were duplicate publications.

\section{Data extraction}

Data extracted after study appraisal. Quality assessment was assayed by NOS scale (New Ottawa Scale). For this purpose, a form designed with multiple pieces of information and the fundamental data needed for analysis (participants, interventions, outcomes, and study quality). The following information extracted and recorded: the first author, the year of publication, study location, number of patients in the treatment and control groups, average group age, group gender, the systemic magnesium dose, mortality, the incidence and types of arrhythmias (supraventricular and ventricular arrhythmias) and mortality. Two authors evaluated independently all included trials and extracted data on the basis of a standard protocol extraction. In cases which needed more information, the articles' writers contacted for supplementary data or further elucidation. 
Disagreements about study eligibility resolved by group discussion. The data entered into Microsoft Excel.

\section{Statistical analysis}

One of the main objectives of this study was to evaluate the incidence of arrhythmia; therefore, the binomial distribution used to calculate the variance in each study and Weighted Average used to combine arrhythmia rate in different studies. Each study weight was proportional to its inverse of the variance. The odds ratio (OR) with a confidence interval of $95 \%$ computed as the effect measure for both individual trials and pooled estimates. For dichotomous data (adverse effects), the Peto odds ratio (to account for the potential of 0 counts in the cells for low-frequency outcomes) and 95\% CI reported.

Statistical heterogeneity evaluated in studies using Q and $\mathrm{I}^{2}$ Cochran statistics. When the results of studies were heterogeneous, the analysis performed using a random-effects model. Also, wherever there was no heterogeneity for the outcome, the fix effects model used to pool analysis and verses. Thus, in this meta-analysis, two main approaches used: the fix effects model and the random-effects model.

Subgroup analyses carried out to investigate the dosage effect of magnesium used $(<10 \mathrm{~g},>10 \mathrm{~g})$ and clinical settings (surgery and not surgery) on the evaluated outcomes. We conducted a meta-regression analysis with sample size, mean age and magnesium dose as independent variables and $\log$ OR as the dependent variable to assess sources of heterogeneity. Integrated estimations and the related confidence interval of $95 \%$ evaluated using forest plots as visuals. Funnel plots and Egger test used to examine publication bias. Values of $p<0 / 05$ considered as valid for heterogeneity tests. The analysis conducted with software R (version 3.2.1) and STATA (version 11.1). All statistical tests were two-sided.

\section{Results}

\section{Selected articles}

In this meta-analysis, we first identified 253 clinical trials. By manual search of the bibliographies and reference lists of these articles, we identified another 61 additional articles. Altogether, 314 articles identified through the literature search and 43 of them eliminated because of being repetitive. Article selection completed considering three steps: title, abstract and the full text. After the initial screening of clinical trials, 31 papers excluded with unrelated titles. In a secondary screening of the abstracts, 190 papers excluded with unrelated abstracts. In the next step and after a full-text review, another 28 article excluded; finally, twenty-two published articles from 1986 to 2017 [12-33] selected to be appropriate for the final analysis (Fig. 1). Collected number of participants were 6061 individuals, which contained 2987 in Magnesium and 3074 in the placebo group respectively. Table 1 summarizes the characteristics of the eligible studies.

\section{Ventricular arrhythmias (ventricular tachycardia or ventricular fibrillation)}

Table 2 represents the total rate of arrhythmias after meta-analysis of the extracted data. As seen in this table, thirteen studies [12-14, 16-20, 23, 27, 29, 31, 32] included for evaluating the prevalence of the ventricular arrhythmia. The prevalence of ventricular tachycardia in the group receiving magnesium sulfate and placebo was $5.67 \%$ (95\% CI, $1.38-11.97)$ and $15.04 \%$ (95\% CI, 6.47-26.06) respectively.

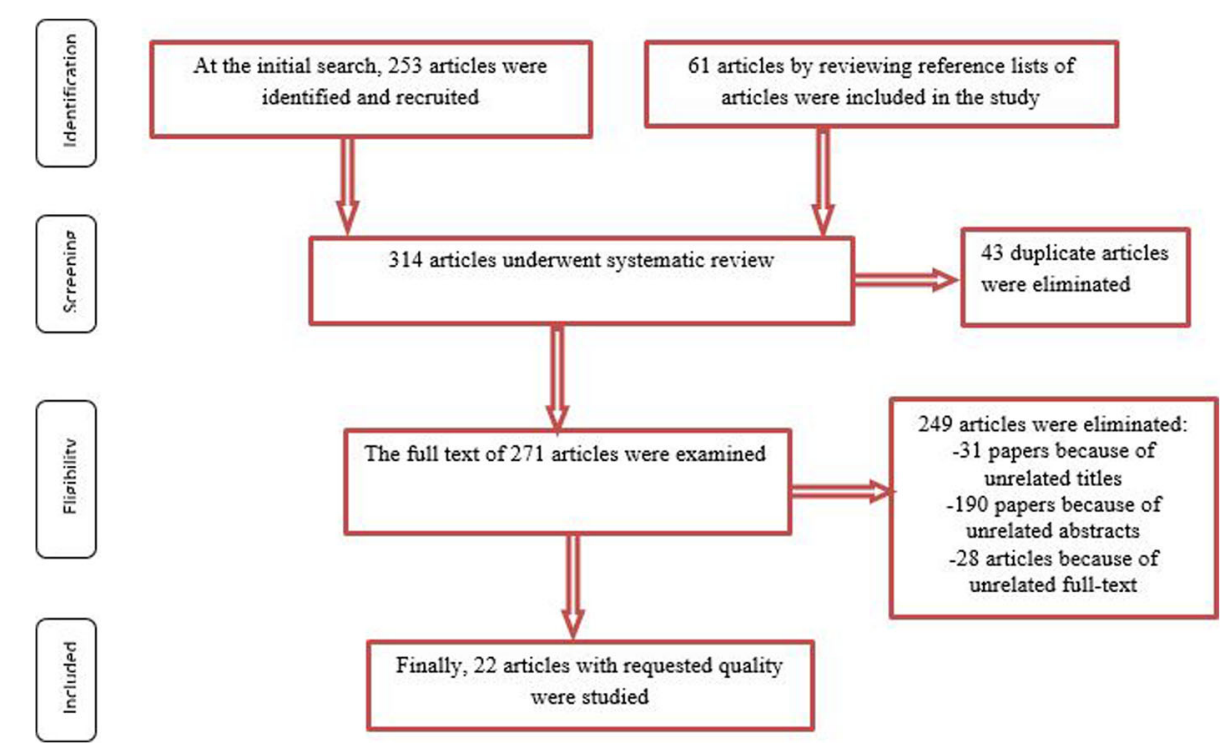

Fig. 1 Flowchart steps of the systematic review and meta-analysis 
Table 1 General characters of studies entered meta-analysis

\begin{tabular}{|c|c|c|c|c|c|c|c|c|}
\hline \multirow[t]{2}{*}{ Authors } & \multirow{2}{*}{$\begin{array}{l}\text { Year of } \\
\text { Publication }\end{array}$} & \multirow[t]{2}{*}{ Country } & \multirow{2}{*}{$\begin{array}{l}\text { Clinical } \\
\text { settings }\end{array}$} & \multicolumn{2}{|c|}{ number } & \multicolumn{2}{|l|}{ Mean Age } & \multirow[t]{2}{*}{ Treatment } \\
\hline & & & & $\mathrm{Mg}$ & $P$ & $\mathrm{Mg}$ & $\mathrm{p}$ & \\
\hline L.F. Smith ${ }^{12}$ & 1986 & U.K. & Not surgery & 92 & 93 & $59.7 \pm 0.9$ & $58.4 \pm 1.1$ & $65 \mathrm{mmol} \mathrm{MgSO} 4$ over $24 \mathrm{~h}$ \\
\hline Rasmussen $\mathrm{HS}^{13}$ & 1987 & Denmark & Not surgery & 55 & 75 & 64.6 & 67.6 & $12 \mathrm{mmol} \mathrm{MgSO} 4$ over $24 \mathrm{~h}$ \\
\hline Shechter.M ${ }^{14}$ & 1990 & Israel & Not surgery & 50 & 53 & $64 \pm 10$ & $63 \pm 11$ & $22 \mathrm{~g} \mathrm{MgSO} 4$ over $24 \mathrm{~h}$ \\
\hline M.Thiigersen. $A^{15}$ & 1993 & Sweden & Not surgery & 54 & 55 & $67 \pm 10$ & $67 \pm 11$ & $50 \mathrm{mmol} \mathrm{MgSO} 4$ over $20 \mathrm{~h}$ \\
\hline Roffe. $C^{16}$ & 1994 & U.K. & Not surgery & 22 & 26 & $65.7 \pm 12.7$ & $60.2 \pm 9.7$ & $73 \mathrm{mmol} \mathrm{MgSO} 4$ over $24 \mathrm{~h}$ \\
\hline Bhargava. $B^{17}$ & 1995 & India & Not surgery & 40 & 38 & $58 \pm 10$ & $56 \pm 8$ & $65 \mathrm{mmol} \mathrm{MgSO} 4$ over $24 \mathrm{~h}$ \\
\hline Karmy-Jones. $R^{18}$ & 1995 & Canada & CABG & 46 & 54 & $64.5 \pm 7.9$ & $60.2 \pm 11.9$ & $2.4 \mathrm{~g} \mathrm{MgSO} 4$ over $24 \mathrm{~h}$ \\
\hline Shakerinia. $T^{19}$ & 1996 & Iran & CABG & 25 & 25 & $67.2 \pm 8.3$ & $64.9 \pm 6.7$ & $15 \mathrm{mmol} / \mathrm{L} \mathrm{MgSO} 4$ over $24 \mathrm{r}$ \\
\hline Raghu. $C^{20}$ & 1999 & India & Not surgery & 169 & 181 & $52.9 \pm 11$ & $53.1 \pm 10.8$ & $18 \mathrm{~g} \mathrm{MgSO} 4$ over $24 \mathrm{~h}$ \\
\hline Parikka. $H^{21}$ & 1999 & Finland & Not surgery & 31 & 26 & $60 \pm 6$ & $59 \pm 6$ & $70 \mathrm{mmol} \mathrm{MgSO} 4$ over $24 \mathrm{~h}$ \\
\hline Treggiari-Venzi MM²2 $^{22}$ & 2000 & Switzerland & CABG & 47 & 51 & 65 & 65 & $4 \mathrm{~g}$ MgSO 4 over $24 \mathrm{~h}$ \\
\hline M. Santoro.G $G^{23}$ & 2000 & Italy & Angioplasty & 75 & 75 & $60 \pm 11$ & $60 \pm 12$ & $7 \mathrm{~g} \mathrm{MgSO} 4$ over $5 \mathrm{~h}$ \\
\hline Toraman $\mathrm{F}^{24}$ & 2001 & Turkey & CABG & 100 & 100 & $62 \pm 6.7$ & $61.4 \pm 8.7$ & $0.8 \mathrm{~g} \mathrm{MgSO} 4$ over $24 \mathrm{~h}$ \\
\hline Nakashima $\mathrm{H}^{25}$ & 2004 & Japan & Angioplasty & 89 & 91 & $67 \pm 11$ & $69 \pm 11$ & $20 \mathrm{~g} \mathrm{MgSO} 4$ over $24 \mathrm{~h}$ \\
\hline Ebadi.A ${ }^{26}$ & 2008 & Iran & CABG & 81 & 81 & $61.6 \pm 5.5$ & $61.7 \pm 8.5$ & 2 g MgSO4 over $24 \mathrm{~h}$ \\
\hline Tiryakioglu. $0^{27}$ & 2009 & Turkey & CABG & 64 & 64 & $58 \pm 8$ & $57.6 \pm 8.8$ & 3 g MgSO 4 over $24 \mathrm{~h}$ \\
\hline Cook RC ${ }^{28}$ & 2009 & Canada & CABG & 462 & 465 & - & - & $5 \mathrm{~g} \mathrm{MgSO} 4$ over $24 \mathrm{~h}$ \\
\hline MoeenVaziri MT $^{29}$ & 2009 & Iran & CABG & 25 & 26 & $60.1 \pm 8.9$ & $60.8 \pm 10.5$ & $30 \mathrm{mg} / \mathrm{kg} \mathrm{MgSO} 4$ in $5 \mathrm{~min}$ \\
\hline Tabari. $M^{30}$ & 2009 & Iran & CABG & 60 & 60 & $61.3 \pm 0.6$ & $58.4 \pm 10.3$ & $4.5 \mathrm{~g} \mathrm{MgSO} 4$ over $24 \mathrm{~h}$ \\
\hline Mhaskar DM"31 & 2013 & India & Not surgery & 50 & 50 & $59.1 \pm 13.4$ & $59.5 \pm 15.03$ & $20 \mathrm{~g} \mathrm{MgSO} 4$ over $24 \mathrm{~h}$ \\
\hline Abbas $\mathrm{SH}^{32}$ & 2015 & Pakistan & CABG & 130 & 130 & $51.7 \pm 10.2$ & $51.7 \pm 10.2$ & $1 \mathrm{~g} \mathrm{MgSO} 4$ over $24 \mathrm{~h}$ \\
\hline Mohammadzadeh $\mathrm{A}^{33}$ & 2017 & Iran & CABG & 125 & 125 & $60.8 \pm 7.6$ & $61.3 \pm 6.6$ & $30 \mathrm{mg} / \mathrm{kg} \mathrm{MgSO} 4$ in $5 \mathrm{~min}$ \\
\hline
\end{tabular}

Notes: $\mathrm{Mg}$, magnesium; $\mathrm{P}$, placebo; $\mathrm{CABG}$, coronary artery bypass grafting

Moreover, the prevalence of ventricular fibrillation in the magnesium sulfate group was $2.13 \%$ (95\% CI, 0.00-6.59) compared to $4.43 \%$ (95\% CI, $0.31-11.69$ ) in the placebo group. The total rate of ventricular arrhythmia was $11.88 \%$ (95\% CI, 6.71-11.17) and 24.24\% (95\% CI, 14.52-35.43) within the magnesium and placebo groups respectively.

We also compared patients with and without arrhythmia in magnesium and placebo groups to determine the association between magnesium and the incidence of ventricular arrhythmias (Table 3).

The present meta-analysis with a fixed-effect model showed no difference in ventricular fibrillation within the magnesium group compared with placebo $(\mathrm{OR}=0.69$, $95 \%$ CI, 0.47-1.01; $\left.\mathrm{I}^{2}=48.9 \%, p=0.098\right)$; however a significant decrease observed in ventricular tachycardia between magnesium and placebo groups $(\mathrm{OR}=0.65$, 95\% CI, 0.50-0.85; $\left.\mathrm{I}^{2}=55.6 \%, p=0.035\right)$. By using random effects model this meta-analysis showed that magnesium could decrease ventricular arrhythmias compared with placebo $(\mathrm{OR}=0.32,95 \%$ CI $0.16-0.49$; $p<0.001$, Fig. 2). There was heterogeneity among trials $\left(\mathrm{I}^{2}=69.7 \% ; p=0.000\right)$.

\section{Supraventricular arrhythmias (atrial fibrillation or supraventricular tachycardia)}

As shown in Table 2, fourteen studies [13, 15-19, 22, 24, 26-28, 30-32] reported the prevalence of supraventricular arrhythmia. The incidence of arrhythmias was as follows: atrial fibrillation was 9.72\% (95\% CI, 3.31-18.63) within the magnesium sulfate group and $22.37 \%$ (95\% CI, 15.86-29.59) within the placebo group. Supraventricular tachycardia was $4.90 \%$ in the magnesium group (95\% CI, $0.84-11.28)$ and $14.62 \%$ in the placebo group(95\% CI, 7.26-23.82). The total rate of supraventricular arrhythmia was $10.36 \%$ (95\% CI, 5.55-16.32) and $23.91 \%$ (95\% CI, 18.82-29.38) within the magnesium and placebo groups respectively.

Random effects analysis showed a significant decrease in atrial fibrillation comparing magnesium with placebo $\left(\mathrm{OR}=0.46,95 \% \mathrm{CI}, 0.28-0.76 ; \mathrm{I}^{2}=76.9 \%, p=0.000\right)$; also a reduction in supraventricular tachycardia observed via fixed-effect model $\left(\mathrm{OR}=0.65,95 \% \mathrm{CI}, 0.50-0.85 ; \mathrm{I}^{2}=48.5 \%\right.$; $p=0.035$ ). Overall, meta-analysis with random effects model showed that magnesium could decrease supraventricular arrhythmia compared with placebo $(\mathrm{OR}=0.42,95 \% \mathrm{CI}$ 
Table 2. Arrhythmias prevalence using Random Effect Meta-Analysis

\begin{tabular}{|c|c|c|c|c|c|c|}
\hline Type of arrhythmia & Treatment & $\begin{array}{l}\text { Number } \\
\text { of studies }\end{array}$ & Prevalence\% & $\begin{array}{l}\text { Confidence interval } \\
95 \%(\mathrm{Cl} \% 95)\end{array}$ & $\begin{array}{l}\text { Heterogeneity } \\
\text { index }\left.\right|^{2}(\%)\end{array}$ & $P$ value \\
\hline \multirow[t]{2}{*}{ Ventricular tachycardia } & Magnesium & 7 & 5.67 & $1.38-11.97$ & 71.81 & 0.003 \\
\hline & placebo & 7 & 15.04 & $6.47-26.06$ & 88.9 & 0.00 \\
\hline \multirow[t]{2}{*}{ Ventricular fibrillation } & Magnesium & 7 & 2.13 & $0.00-6.59$ & 76.81 & 0.00 \\
\hline & Placebo & 7 & 4.43 & $0.31-11.69$ & 86.09 & 0.00 \\
\hline \multirow[t]{2}{*}{ Total of Ventricular arrhythmia } & Magnesium & 13 & 11.88 & $6.71-18.17$ & 82.99 & 0.00 \\
\hline & Placebo & 13 & 24.24 & $14.52-35.43$ & 92.11 & 0.00 \\
\hline \multirow[t]{2}{*}{ Atrial fibrillation } & Magnesium & 9 & 9.72 & $3.31-18.63$ & 92.15 & 0.00 \\
\hline & Placebo & 9 & 22.37 & $15.86-29.59$ & 85.3 & 0.00 \\
\hline \multirow[t]{3}{*}{ Supraventricular tachycardia } & Magnesium & 6 & 4.90 & $0.84-11.28$ & 75.36 & 0.00 \\
\hline & Placebo & 6 & 14.62 & $7.26-23.82$ & 78.76 & 0.00 \\
\hline & Magnesium & 14 & 10.36 & $5.55-16.32$ & 87.16 & 0.00 \\
\hline $\begin{array}{l}\text { Total of supraventricular } \\
\text { arrhythmia }\end{array}$ & Placebo & 14 & 23.91 & $18.82-29.38$ & 75.10 & 0.00 \\
\hline \multirow[t]{2}{*}{ Bradycardia } & Magnesium & 4 & 6.46 & $0.71-12.21$ & 78.9 & 0.00 \\
\hline & Placebo & 4 & 7.2 & $1.03-1.37$ & 79.8 & 0.00 \\
\hline \multirow[t]{2}{*}{ Total Arrhythmia } & Magnesium & 22 & 41 & $11.44-21.0$ & 85.89 & 0.00 \\
\hline & Placebo & 22 & 30.85 & 25.07-39.63 & 86.21 & 0.00 \\
\hline
\end{tabular}

$0.22-0.65 ; p<0.001$, Fig. 3). There was significant heterogeneity among trials $\left(\mathrm{I}^{2}=77.6 .4 \% ; p=0.000\right)$, (Table 3 ).

\section{Bradycardia}

Among reviewed studies, four articles reported the prevalence of bradycardia. The rate of bradycardia in the magnesium sulfate and placebo groups was 6.46\% (95\% $\mathrm{CI}, 0.71-12.21)$ and $7.2 \%$ (95\% CI, 1.03-1.37) respectively (Table 2). Random effects meta-analysis did not show a beneficial effect of magnesium on the reduction of bradycardia (OR $=1.29,95 \%$ CI $0.99-1.69 ; p=0.329$ ). The reviewed studies showed limited evidence of heterogeneity $\left(\mathrm{I}^{2}=12.7 \% ; p>0.001\right)$, (Table 3 ).

\section{Subgroup analyses}

It was clear that some factors might influence the associations between magnesium and the incidence of cardiac arrhythmias. Therefore, we conducted subgroup analyses to minimize heterogeneity among various studies. In the current study, the effect of magnesium consumption versus placebo on the reduction of cardiac arrhythmias examined by the dosage of magnesium ( $<10 \mathrm{~g},>10 \mathrm{~g}$ ); fourteen trials used magnesium less than $10 \mathrm{~g}$ and eight used magnesium $10 \mathrm{~g}$ or more within the first $24 \mathrm{~h}$. We found a significant decrease in cardiac arrhythmias comparing magnesium with placebo in both groups (magnesium $<10 \mathrm{~g} \mathrm{OR}=0.42$, 95\% CI: $0.24-0.59 ; \mathrm{I} 2=71.0 \%, p=0.000$ and magnesium $\geq 10$ g OR $=0.34,95 \%$ CI: $0.08-0.60 ; \mathrm{I} 2=90.1 \%$, $\mathrm{p}=0.000$ ).

We also performed subgroup meta-analysis based on the clinical settings; surgery or not surgery. Nine trials evaluated the effect of magnesium consumption on the incidence of arrhythmias in nonsurgical patients. The results of the meta-analysis showed a significant decrease comparing magnesium with placebo $(\mathrm{OR}=0.33,95 \% \mathrm{CI}$,

Table 3 Magnesium administration and the incidence and type of arrhythmias compared to placebo

\begin{tabular}{|c|c|c|c|c|}
\hline \multirow[t]{2}{*}{ Type of fractures } & \multirow{2}{*}{$\begin{array}{l}\text { Summary } \\
\text { odds ratio (OR) }\end{array}$} & \multirow{2}{*}{$\begin{array}{l}95 \% \text { confidence } \\
\text { interval }\end{array}$} & \multicolumn{2}{|c|}{ Between studies } \\
\hline & & & $1^{2}$ & $\begin{array}{l}\mathrm{p} \text { for } \\
\text { heterogeneity }\end{array}$ \\
\hline $\begin{array}{l}\text { Ventricular tachycardia } \\
\text { Ventricular fibrillation } \\
\text { Total of Ventricular arrhythmia }\end{array}$ & $\begin{array}{l}0.65 \\
0.69 \\
0.38\end{array}$ & $\begin{array}{l}0.50-0.85 \\
0.47-1.01 \\
0.23-0.64\end{array}$ & $\begin{array}{l}55.6 \% \\
48.9 \% \\
79.0 \%\end{array}$ & $\begin{array}{l}0.035 \\
0.098 \\
0.000\end{array}$ \\
\hline $\begin{array}{l}\text { Atrial Fibrillation } \\
\text { Supraventricular tachycardia } \\
\text { Total of Supraventricular arrhythmia }\end{array}$ & $\begin{array}{l}0.46 \\
0.48 \\
0.43\end{array}$ & $\begin{array}{l}0.28-0.76 \\
0.33-0.70 \\
0.28-0.65\end{array}$ & $\begin{array}{l}76.9 \% \\
48.5 \% \\
73.4 \%\end{array}$ & $\begin{array}{l}0.000 \\
0.084 \\
0.000\end{array}$ \\
\hline Bradycardia & 1.29 & $0.99-1.69$ & 12.7 & 0.329 \\
\hline Total Arrhythmia & 0.41 & $0.29-0.58$ & 82.1 & 0.000 \\
\hline
\end{tabular}




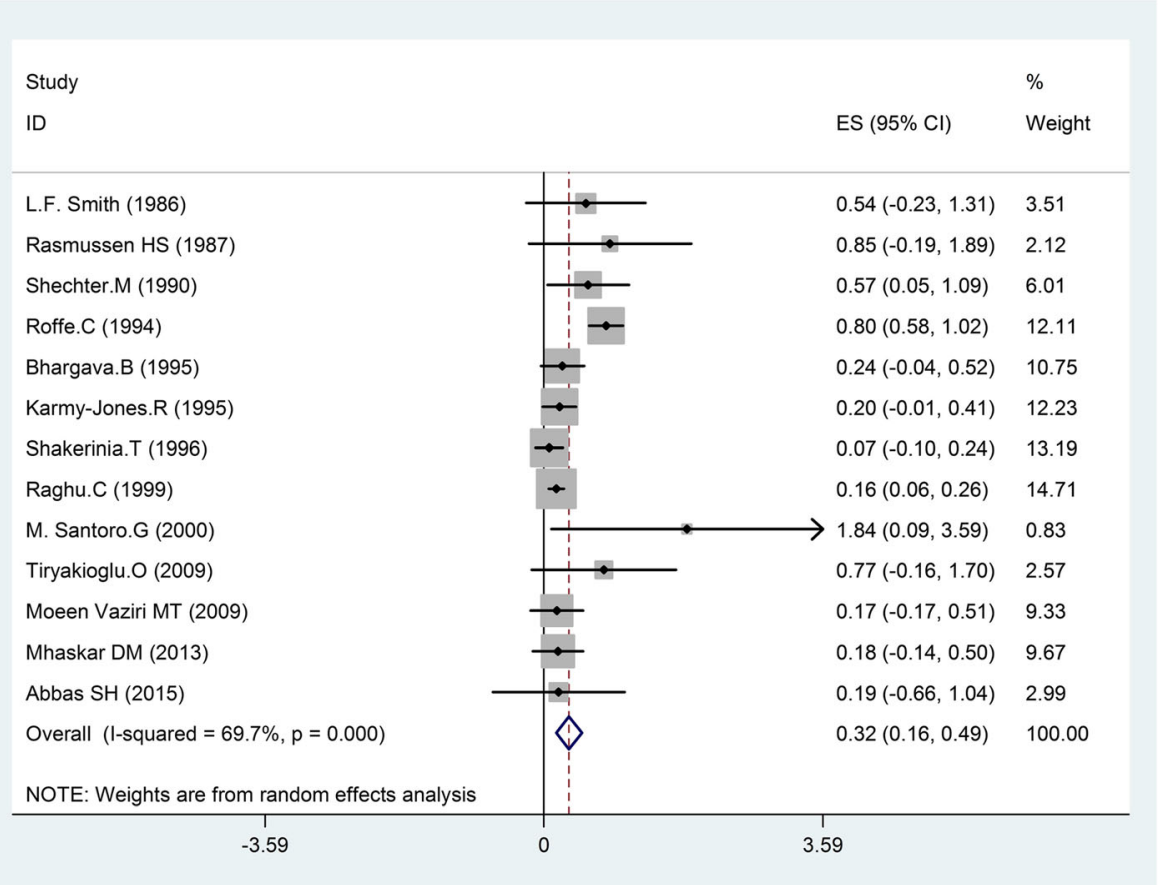

Fig. 2 Forest plot and the rate of ventricular arrhythmias (left: magnesium, right: placebo).Square represents effect estimate of individual studies with their $95 \%$ confidence intervals with size of squares proportional to the weight assigned to the study in the meta-analysis. In this chart, studies are stored in order of the year of publication and author's names, based on a random effects model

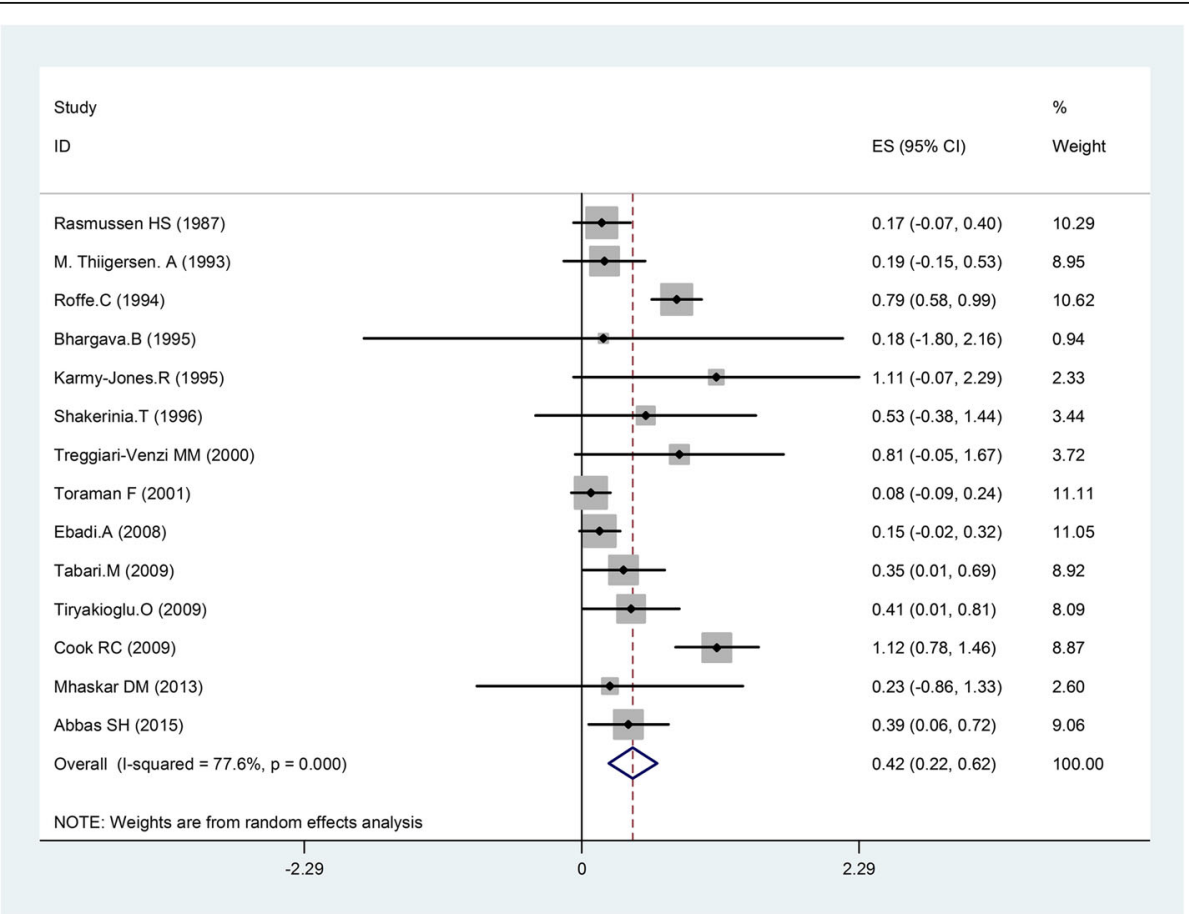

Fig. 3 Forest plot and the rate of supraventricular arrhythmias (left: magnesium, right: placebo). Square represents effect estimate of individual studies with their $95 \%$ confidence intervals with size of squares proportional to the weight assigned to the study in the meta-analysis. In this chart, studies are stored in order of the year of publication and author's names, based on a random effects model 
$0.10-0.57 ; \mathrm{I} 2=88.7 \%, p=0.000)$. Also, thirteen trials performed in surgical patients and showed that magnesium consumption could have a positive effect in reducing cardiac arrhythmias $(\mathrm{OR}=0.43,95 \% \mathrm{CI} 0.24-0.62$; $\mathrm{I} 2=73.3 \%, \mathrm{p}=0.000$ ).

The results of subgroup analyses showed that the dose of magnesium used or the clinical settings did not affect the reduction of arrhythmias.

To find the source of heterogeneity a meta-regression performed. As seen in Table 4, the association between sample size, mean age, published year, the consumed dose of magnesium and the effect size of the outcomes evaluated. Our results showed that there was no significant association between the reduction of ventricular arrhythmias and sample size $(p=573)$, mean age $(p=553)$, published year $(p=283)$, and the consumed dose of the magnesium $(p=410)$.

\section{Publication Bias}

Figure 4 presents the Begg's funnel plot for publication bias in the risk difference analysis of the effect of magnesium in reducing ventricular arrhythmias. According to the publication bias figure, the effect of bias was not significant when Begg's funnel plot evaluated $(p=0.204$, Fig. 4); $P$-values for Egger's regression asymmetry test were 0.008; thus, the Egger tests revealed the evidence of publication bias in this study.

\section{Discussion}

Cardiac arrhythmia is caused by a wrong rate or rhythm of the heartbeat, which are under the control of the cardiac conduction system [34]. Magnesium sulfate is frequently used to reduce cardiac arrhythmias in patients with the acute coronary syndrome [35]. Numerous attempts are in action to diminish cardiac arrhythmias. This study is a meta-analysis of previously conducted studies comparing magnesium consumption versus placebo control in reducing the incidence of cardiac arrhythmia; the current systematic review and meta-analysis of these twenty-two randomize control trials found a positive correlation between the administrations of magnesium sulfate and the reduction of cardiac arrhythmias.

Our results were consistent with those of the previous meta-analyses which evaluated the effect of magnesium

Table 4 Source of heterogeneity by multivariate metaregression analysis

\begin{tabular}{llll}
\hline Factors & Coefficient & Standard error & $P$ \\
\hline Published year & -.0121418 & .010758 & 0.283 \\
Sample size & -.0010426 & .0017948 & 0.573 \\
Mean age & .0118355 & .0192186 & 0.553 \\
Dose of Magnesium & .2159504 & .0109332 & 0.410 \\
\hline
\end{tabular}

on the incidence of arrhythmias. A meta-analysis of eight trials included 930 patients with acute myocardial infarction, showed the beneficial effect of magnesium to prevent arrhythmias. Horner's study showed that the administration of magnesium in acute myocardial infarction associated with $49 \%$ reduction in ventricular arrhythmias and 54\% reduction in supraventricular tachycardia [36]. A meta-analysis of seventeen trials with 2069 patients reported that magnesium administration could reduce the risk of supraventricular arrhythmias by $23 \%$ (atrial fibrillation by 29\%) and of ventricular arrhythmias by $48 \%$ after cardiac surgery [37]. Our meta-analysis showed that magnesium could decrease the risk of ventricular arrhythmias about $32 \%$ and supraventricular arrhythmias about $42 \%$ respectively.

One of our results was that magnesium sulfate could reduce the incidence of supraventricular arrhythmias more than ventricular arrhythmias. However, the effect of magnesium in reducing the incidence of ventricular arrhythmias has not investigated as widely as the same for supraventricular arrhythmias. A meta-analysis of twenty studies with 3696 patients who underwent coronary artery bypass did not find any effect of magnesium on the incidence of ventricular arrhythmias; the authors identified the effect of magnesium sulfate in reducing postoperative supraventricular arrhythmias when examined by lower-quality studies [38].

This study suggests that magnesium sulfate administration reduces supraventricular arrhythmia. Moreover, the observed effects were greater for atrial fibrillation. The most common arrhythmia after coronary artery bypass graft is atrial fibrillation. Alghamdi and colleagues in a meta-analysis of eight randomized controlled trials revealed that the use of intravenous magnesium associated with a significant reduction in the incidence of atrial fibrillation after coronary artery bypass surgery [39]. Another meta-analysis of twenty-two trials with 2896 patients showed that there was an overall reduction in atrial fibrillation after magnesium administration [40]. A meta-analysis of 2490 patients from twenty randomized trials concluded that magnesium administration could be an effective prophylactic measure for prevention of the postoperative atrial fibrillation [41]. Another meta-analysis of seven clinical trials with 1028 participants revealed that intravenous magnesium reduced the incidence of postoperative atrial fibrillation about $36 \%$ [42]. Many of the conducted studies encouraged the use of intravenous magnesium to prevent postoperative atrial fibrillation after coronary artery bypass grafting. The present meta-analysis was consistent with previous studies; we confirmed the previous results and concluded that magnesium administrating could be useful in prevention and treatment of various cardiac arrhythmias. 


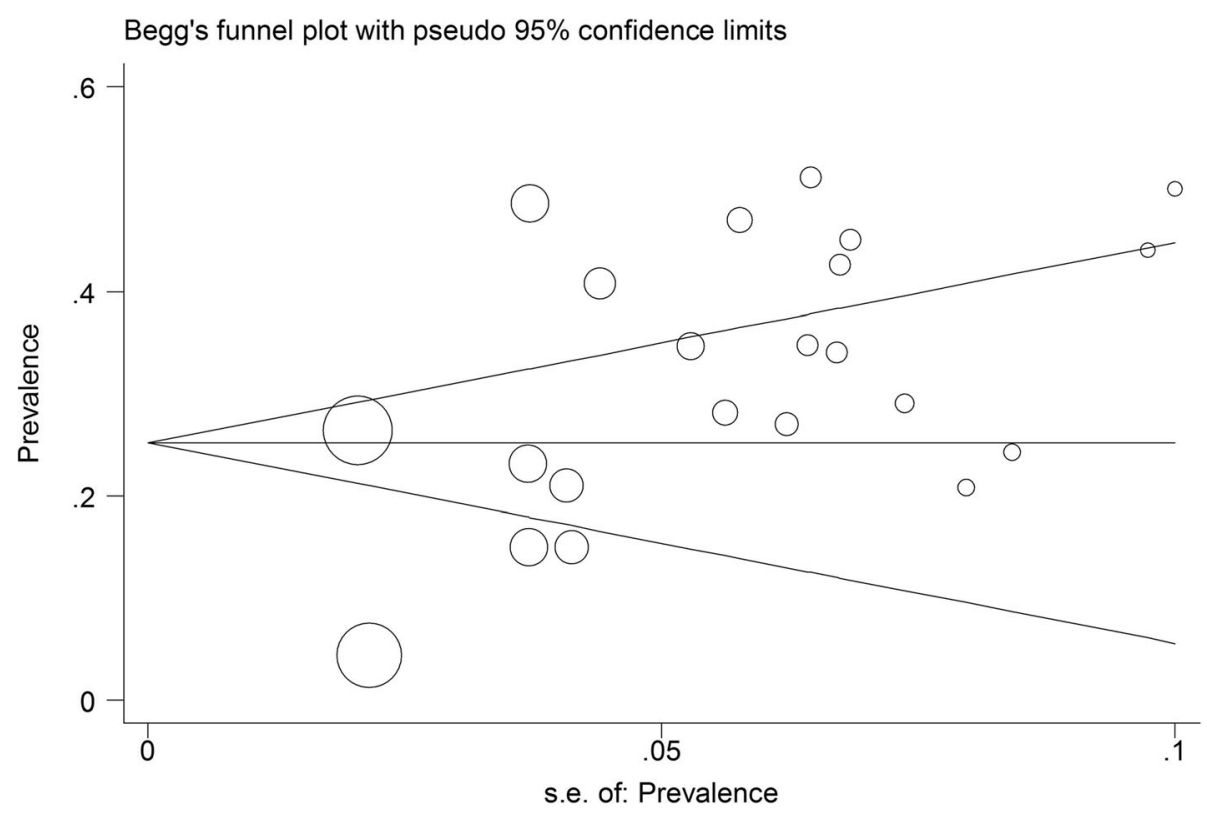

Fig. 4 Begg's funnel plot for publication bias in the risk difference analysis

As discussed above, several meta-analyses have explored the effects of magnesium administration and cardiac arrhythmias, but there was also data not included. Furthermore, there have been further developments and newer trials since the publication of previous meta-analyses, which did not include these trials. In fact, this study is also the largest one which examined the effect of magnesium on the incidence of cardiac arrhythmias.

Magnesium plays an essential role in many fundamental biological processes, for example, it participates in many enzymatic reactions and many ion channels functions [34]. Magnesium also is a cofactor of the membrane $\mathrm{Na}-\mathrm{K}$ pump; it regulates the outward $\mathrm{K}+$ movement and potassium is transported equally in both directions when $\mathrm{Mg} 2+$ is absent $[43,44]$. Magnesium deficiency can reduce the amount of intracellular $\mathrm{K}+$ and the pump's activity, which leads to partial depolarization and changes in the activity of many potential-dependent membrane channels $[43,44]$. So, its deficiency also disturbs the resting membrane potential of the cardiac cells and results in cardiac arrhythmias [44].

Hypomagnesaemia is common among patients with cardiovascular diseases [45]. Therefore, measurement of the serum magnesium level of patients with cardiovascular disease before surgery is necessary and indicate injection of magnesium sulfate to prevent these complications. Hypomagnesaemia in cardiovascular disease may occur due to various reasons such as treatment of hypertension with diuretics, diabetic patients, and patients with cardiomyopathy [46].

Magnesium deficiency is an important factor responsible for supraventricular and ventricular arrhythmias
[34]. Beluri and colleagues found that the risk of ventricular arrhythmias in magnesium deficiency increased dramatically and suggested that hypomagnesemia could be considered one of the most important causes of ventricular arrhythmias [47]. Hypomagnesemia in patients with congestive heart failure causes arrhythmia. Fall Solomon and colleagues found that $55 \%$ of patients with congestive heart failure suffer hypomagnesemia, which results in ventricular premature beats and atrial fibrillation [48].

All these findings indicate the importance of serum magnesium monitoring level in cardiac patients. Therefore, by checking and correcting serum magnesium level, it is possible to prevent many cardiac arrhythmias and improve the care of cardiac patients.

This meta-analysis had several limitations. First, there was a lack of uniformity in the reviewed trials regarding the clinical settings and the amount of magnesium administered. For example, some study was among revascularized patients (CABG or angioplasty) while others in non-surgical patients; however, we performed a meta-analysis and concluded that the effect of magnesium on the incidence of arrhythmias not affected by either clinical settings or the amount of magnesium administered. Secondly, we were unable to conduct a subgroup analysis regarding the concurrent use of other antiarrhythmic medications. Insufficient available data about the concurrent use of other antiarrhythmic agents, which could modify effect size, prevented us from the evaluation of such cases. Third, in a meta-analysis sample size and standard deviation are very important in combining the results of studies and may be influenced the evaluated outcomes. Fourth, the possible effects of publication bias inherent in 
any meta-analysis could not be ruled out. Finally, some identified studies presented defective quantitative data and could not be included in this meta-analysis.

\section{Conclusion}

The present meta-analysis showed that the total rate of cardiac arrhythmia was significantly lower in the group receiving magnesium sulfate than placebo The current finding also showed that magnesium consumption would decrease ventricular and supraventricular arrhythmias compared with placebo. In conclusion, our study suggested that administration of magnesium sulfate could be safe, effective and cost-effective in the prevention of many cardiac arrhythmias. Therefore, by checking and correcting serum magnesium level, it may be possible to prevent a large proportion of cardiac arrhythmias and improve cardiac patient's health. However, other studies should be done about the dose and the time of adding magnesium sulfate until proved that this method is effective in the prevention of cardiac arrhythmias.

\section{Abbreviations}

CABG: Coronary Artery Bypass Grafting; PCl: Percutaneous Coronary Intervention

\section{Acknowledgements}

The authors extend their gratitude to the Social Determinants of Health Research Center, Yasoj University of Medical Sciences.

\section{Availability of data and materials}

All data generated or analyzed during this study are included in this published article.

\section{Authors' contributions}

ShS and MM designed the conception of the study; KS and FS focus of the statically analysis; PA, technical support and conceptual advise. All authors contributed to the drafted the manuscript, revised it critically and approved the final version.

\section{Ethics approval and consent to participate}

Not applicable.

\section{Consent for publication}

Not applicable.

\section{Competing interests}

The authors declare that they have no competing interests.

\section{Publisher's Note}

Springer Nature remains neutral with regard to jurisdictional claims in published maps and institutional affiliations.

\footnotetext{
Author details

'Department of Cardiac Surgery, Yasuj University of Medical Science, Yasuj, Iran. ${ }^{2}$ Proteomics Research Center, Shahid Beheshti University of Medical Sciences, Tehran, Iran. ${ }^{3}$ Social Determinants of Health Research Center, Yasuj University of Medical Sciences, Yasuj, Iran. ${ }^{4}$ Department of Social Medicine, School of Medicine, Ilam University of Medical Sciences, Ilam, Iran. ${ }^{5}$ Department of Cardiology, Faculty of Medicine, Zanjan University of Medical Sciences, Zanjan, Iran.
}

Received: 14 September 2017 Accepted: 7 June 2018

Published online: 28 June 2018

\section{References}

1. Chung M, Asher R, Yamada D, Eagle K. Arrhythmias after cardiac and noncardiac Surgery. In: Podrid P, Kowey P, editors. Cardiac arrhythmia. 2nded. Philadelphia: Lippincott Williams Wilkins; 2001. p. 631-8.

2. Dipiro JT, Al. Talbea R, Yee g C, et al. Pharmacotherapy, vol. 976. 6th ed. New York: McGraw-Hill; 2005.

3. Kaplan JA, Reich DL, Lake CL, et al. Kaplan's cardiac anesthesia, vol. 268. 5th ed. Philadelphia: Saunders; 2006.

4. Butterworth J, Prielipp R. Endocrin, metabolic and electrolyte responses. In: Gravlec G, Davis R, Kurusz M, Utley J, editors. Cardiopulmonary Bypass. 2nded. Philadelphia: Lippincott Williams Wilkins; 2000. p. 358-60.

5. Shirey T. Monitoring magnesium to guid magnesium therapy for heart surgery. J Anesth. 2004;18:118-28.

6. Fanning WJ, et al. Prophylaxis of atrial fibrillation with magnesium sulfate after coronary artery bypass grafting. Ann Thorac Surg. 1991;52:529-33.

7. Kaplan M, Kut MS, Demirtas MM. Intravenous magnesium sulfate prophylaxis for artery bypass surgery. J Thorac Cardiavasc Surg. 2003;125:344-52.

8. Pinrad A, Donati F. Magnesium potentiates neuromuscular block with cisatracurium during cardiac surgery. Can J Anaesth. 2003;50:72-8.

9. Yeatman M, Angelini GD, Shnaider H. Magnesium in cardiac arrhythmias digoxin-induced nonparoxysmal atrioventricular junctional tachycardia responsive to parenteral magnesium sulfate. Br J Anaesth. 1988;24:230-40.

10. Wistbacka JO, Koistinen J. Magnasium substitution in elective coronary artery surgery. J Cardiothorac Vasc Anesth. 1995;9:140-6.

11. Antman EM. Early administration of intravenous magnesium to high-risk patients with acute myocardial infarction in the magnesium in coronaries (MAGIC) trial: a randomized controlled trial. Lancet. 2002;360:1189-96.

12. Smith LF, Heagerty AM, Bing RF, Barnett DB. Intravenous infusion of magnesium sulfate after acute myocardial infarction: effects on arrhythmias and mortality. Int J Cardiol. 1986:12:175-80.

13. Rusmussen HS, Suenson M, Mcnairm P, Nbrregard P, Balslevm S. Magnesium infusion reduces the incidence of arrhythmias in acute myocardial infarction. A double-blind placebo-controlled study. Clin Cardiol. 1987;10:351-6.

14. Shechter M, Hod H, Marks N, Behar S, Kaplinsky E, Rabinowitz B. Beneficial effect of magnesium sulfate in acute myocardial infarction. Am J Cardiol. 1990;66:271-4.

15. M. Thiigersen A, Johnson O. O, Wester P. Effects of magnesium infusion on thrombolytic and non-thrombolytic treated patients with acute myocardial infarction. Int J Cardiol 1993:39:13-22.

16. Roffe $\mathrm{C}$, Fletcher $\mathrm{S}$, Woods $\mathrm{KL}$. Investigation of the effects of intravenous magnesium sulfates on cardiac rhythm in acute myocardial infarction. $\mathrm{Br}$ Heart. 1994;71:141-5.

17. Bhargava B, Chandra S, .Agarwal W, Kaul U, Vashishth S, Wasir HS Adjunctive magnesium infusion therapy in acute myocardial infarction. Int J Cardiol 1995; 52: 95-99.

18. Karmy Jones R, Hamilton A, Dzavik V, Allegreto M, Finegan BA, Koshal A. Magnesium sulfate prophylaxis after cardiac operations. Ann Thorac Surg. 1995;59:502-7.

19. Shakerinia T, Ali IM, And Sullivan JA. magnesium in cardioplegia: is it necessary. CJS 1996; 39(5): 397-400.

20. Raghu C, Peddeswara P, Seshagiri Rao D. Protective effect of intravenous magnesium in acute myocardial infarction following thrombolytic therapy. Int J Cardiol. 1999;71:209-15.

21. Parikka H, Toivonen L, Naukkarinen V, Tierala I, Pohjola-Sintonen S, Heikkila J, Nieminen MS. Decreases by magnesium of QT dispersion and ventricular arrhythmias in patients with acute myocardial infarction. Eur Heart J. 1999; 20:111-20.

22. Treggiari-Venzi MM, Waeber JL, Perneger TV, Suter PM, Adamec R, Romand JA. Intravenous amiodarone or magnesium sulfate is not cost-beneficial prophylaxis for atrial fibrillation after coronary artery bypass surgery. $\mathrm{Br} J$ Anaesth. 2000:85(5):690-5.

23. Santoro GM, Antoniucci D, Bolognese L, Valenti R, Buonamici P, Trapani M, Santini A, Filippo Fazzini P. A randomized study of intravenous magnesium in acute myocardial infarction treated with direct coronary angioplasty. Am Heart J. 2000:140:891-7.

24. Toraman F, Karabulut EH, Alhan C, Dagdelen S, Tarcan S. Magnesium infusion dramatically decreases the incidence of atrial fibrillation after coronary artery bypass grafting. Ann Thorac Surg. 2001;72:1256-62. 
25. Nakashima H, Katayama T, Honda Y, Suzuki S, Yano K. Cardioprotective effects of magnesium sulfate in patients undergoing primary coronary angioplasty for acute myocardial infarction. Circ J. 2004;68:23-8.

26. Ebadi A, Mohammad Hosseini F, Tabatabai SK, Rostaminejad A. Evaluation of using IV magnesium sulfate for prevention of postoperative atrial fibrillation arrhythmia in patients undergoing coronary artery bypass grafting. Journal of Armaghan Danesh. 2008;13(2):1-10.

27. Tiryakioglu O, Demirtas S, Ari H, Tiryakioglu SK, Huysal K, Selimoglu O, Ozyazicioglu A. Magnesium sulfate and amiodarone prophylaxis for prevention of postoperative arrhythmia in coronary by-pass operations. J Cardiothorac Surg. 2009;4(8):2-7.

28. Cook RC, Humphries KH, Gin K, Janusz MT, Slavik RS, Pharm D, Bernstein V, Tholin M, Lee MK. Prophylactic Intravenous Magnesium Sulphate in addition to oral blockade does not prevent atrial arrhythmias after coronary artery or Valvular heart surgery a randomized. Controlled Trial Circulation. 2009; 120(15):163-9.

29. Moeen Vaziri MT, Jouibar R, Akhlagh SHA, Janati M. The effect of lidocaine and magnesium sulfate on prevention of ventricular fibrillation in coronary artery bypass grafting surgery. Iran Red Crescent Med J. 2010;12(3):298-301.

30. Tabari M, Soltani Gh, Zirak N, Ghoshayeshi L. the effect of magnesium sulfate on cardiac arrhythmias after open heart surgery. J Med Sci 2009;88.[ article in persian].

31. Mhaskar MM, Mahajan SK, Pawar KC. Significance of serum magnesium levels in reference to acute myocardial infarction and role of intravenous magnesium therapy in prevention of cardiac arrhythmias following myocardial infarction. International Journal of Medicine and Public Health. 2013;3(3):187-91.

32. Abbas S, Khan FJ, Abbas A, Sharif Nassery S, RiaZz W, labal M. Waheed. Prophylactic magnesium and rhythm disorders after open cardiac surgery. Journal of Cardiology \& Current Research. 2015;2(6):00081.

33. Mohammadzadeh A, Towfighi F, Jafari $\mathrm{N}$. Effect of magnesium on arrhythmia incidence in patients undergoing coronary artery bypass grafting. ANZ J Surg. 2017; https://doi.org/10.1111/ans.14056.

34. Cieoelewicz A, Jankowski J, Korzeniowska K, Balcer-Dymel N, Jabecka A. The role of magnesium in cardiac arrhythmias. J Elem s. 2013; https://doi.org/10. 5601/jelem.2013.18.2.11.

35. Shechter M, Hod H, Marks N, Behar S, Kaplinsky E, Rabinowitz B. Beneficial effect of Magnessium sulfate in acute myocardial infarction. Am J Cardiol. 1990;66:271-4

36. Horner SM. Efficacy of intravenous magnesium in acute myocardial infarction in reducing arrhythmias and mortality: meta-analysis of magnesium in acute myocardial infarction. Circulation. 1992;86:774-9.

37. Shiga T, Wajima Z, Inoue T, et al. Magnesium prophylaxis for arrhythmias after cardiac surgery: a meta-analysis of randomized controlled trials. Am J Med. 2004;117:325-33.

38. De Oliveira GS Jr, Knautz JS, Sherwani S, McCarthy RJ. Systemic magnesium to reduce postoperative arrhythmias after coronary artery bypass graft surgery: a meta-analysis of randomized controlled trials. J Cardiothorac Vasc Anesth. 2012;26(4):643-50.

39. Alghamdi AA, Al-Radi OO, Latter DA. Intravenous magnesium for prevention of atrial fibrillation after coronary artery bypass surgery: a systematic review and meta-analysis. J Cardiovasc Surg. 2005;20:293-9.

40. Burgess DC, Kilborn MJ, Keech AC. Interventions for prevention of postoperative atrial fibrillation and its complications after cardiac surgery: a meta-analysis. Eur Heart J. 2006:27:2846-57.

41. Miller S, Crystal E, Garfinkle M, et al. Effects of magnesium on atrial fibrillation after cardiac surgery: a meta-analysis. Heart. 2005;91:618-23.

42. Gu WJ, WU ZJ, WANG PF, AUNG LH, YIN RX. Intravenous magnesium prevents atrial fibrillation after coronary artery bypass grafting: a metaanalysis of 7 double-blind, placebo-controlled, randomized clinical trials. Trials. 2012;13:41

43. ANGUS M, ANGUS Z. Cardiovascular actions of magnesium. Crit Care Clin. 2001;53:299-307.

44. Rude r, Shils ME. Magnesium. In: Modern Nutrition in health and disease, Shils ME, Shike M, Ross AC, Caballero B, Cousins RJ, editors. 10th edition: Lippincott Williams \& Wilkins; 2006.

45. Big RP, Chia R. Magnesium deficiency. Role in arrhythmias complicating acute myocardial infarction? Med J Aust. 1981;1(7):346-8.

46. Al-Ghamdi SM, Cameron EC, Sutton RA. Magnesium deficiency: pathophysiologic and clinical overview. Am J Kidney Dis. 1994;24(5):737-52.
47. Bolouri A, Mehrabi GHA, Salehi M. Evaluation of the prevalence of ventricular tachyarrhythmia in patients with acute myocardial infarction and serum magnesium in Khatam-Al-Anbia hospital, Zahedan, Iran. Zahedan J Res Med Sci, Tabib-e-Shaegh. 2006; 8(2): 93-100.[article in Persian].

48. Fal Soleiman $H$, Kazemi $T$. The serum magnesium level in patients with congestive heart failure. Med J Mashad Univ Med Sci. 2006;90(48):399-404.

\section{Ready to submit your research? Choose BMC and benefit from:}

- fast, convenient online submission

- thorough peer review by experienced researchers in your field

- rapid publication on acceptance

- support for research data, including large and complex data types

- gold Open Access which fosters wider collaboration and increased citations

- maximum visibility for your research: over $100 \mathrm{M}$ website views per year

At BMC, research is always in progress.

Learn more biomedcentral.com/submissions 